\title{
Engineered bacteriophage lysins as novel anti-infectives
}

\author{
Hang Yang, Junping Yu and Hongping Wei* \\ Key Laboratory of Special Pathogens and Biosafety, Center for Emerging Infectious Diseases, Wuhan Institute of Virology, Chinese Academy of Sciences, Wuhan, \\ China
}

Edited by:

Marta Martins, University College

Dublin, Ireland

Reviewed by:

Melinda J. Mayer, Institute of Food Research, UK

Taoufik Ghrairi, Faculty of Medicine Ibn El Jazzar of Sousse, Tunisia Pedro Fernandes, Instituto Superior Tecnico - Universidade de Lisboa, Portugal

*Correspondence:

Hongping Wei, Wuhan Institute of Virology, Chinese Academy of

Sciences, Wuhan 430071, China

e-mail: hpwei@wh.iov.cn
Bacteriophage lysins, the highly evolved specific peptidoglycan hydrolases, have long been demonstrated to be effective enzybiotics in various infectious models. The modular structure of lysins makes it possible to design bioengineered lysins that have desired properties, such as higher activity, or broader killing spectrum. Moreover, lysins can even be engineered to kill Gram-negative bacterial pathogens from without, a property that is not present in natural lysins. In this era of ever increasing multidrug resistant pathogens, engineered lysins represent a new class of enzybiotics that are powerful and readily available to fight antimicrobial resistance.

Keywords: lysin, chimeolysin, artilysin, bacteriophage, lysin engineering, enzybiotics

\section{INTRODUCTION}

Bacteriophage lysins are novel murein hydrolases encoded by dsDNA phages in the late phase of infection cycle for the release of progeny virions (Loessner, 2005). These enzymes are usually genus-specific and highly active against bacterial peptidoglycan and capable of digesting the cell walls of susceptible bacteria, including multidrug resistant Gram-positive pathogens (Fischetti, 2006). Therefore, lysins have been considered as promising anti-infective enzybiotics with potential important applications in medicine and biotechnology in the current age of mounting antimicrobial resistance (Fischetti et al., 2006).

Currently, there are excellent reviews that have dealt with the characteristics of lysins and their applications, both as alternative enzybiotics in medical-oriented in vitro and in vivo tests (Fischetti, 2005; Fenton et al., 2010b; Knoll and Mylonakis, 2014), and as preservatives in the food industry (Callewaert et al., 2011; Oliveira et al., 2012). In the experimental models of sepsis (Schuch et al., 2002; Gilmer et al., 2013), pneumonia (Loeffler et al., 2001; Witzenrath et al., 2009), endocarditis (Entenza et al., 2005), meningitis (Grandgirard et al., 2008), nasopharyngeal infection (Kiser et al., 1999), canine pyoderma (Junjappa et al., 2013), endophthalmitis (Singh et al., 2014), skin and vaginal decolonization (Cheng et al., 2005), lysins have been used as effective anti-infectives to eliminate pathogens systemically and topically from mucosal surfaces and biofilms, including methicillin- and vancomycin-resistant Staphylococcus aureus, vancomycin-resistant Enterococcus faecalis and E. faecium, and penicillin-resistant Streptococcus pneumoniae. According to the opinion of Vincent A. Fischetti, several unique characteristics of lysins makes them attractive enzybiotics over small molecule antibiotics (Fischetti, 2008, 2010). These include (i) their specificity for the pathogens without disturbing the normal microflora, (ii) the low chance of developing bacterial resistance, and (iii) their ability to kill colonizing pathogens on mucosal surfaces. One possible problem of lysins may be their immunogenicity as protein molecules. However, studies thus far have illustrated that lysin-specific antibodies are non-neutralizing both in vitro and in vivo (Rashel et al., 2007; Daniel et al., 2010; Yang et al., 2014), which means that lysins can be used repeatedly in the treatment of infections caused by susceptible pathogens. Clinical trials are being conducted or prepared to assess the safety and pharmacokinetic properties of lysins in humans (Pastagia et al., 2013). For instance, a lysin against staphylococci P128 (George et al., 2012), has already stepped into phase II clinical trial (http://www.clinicaltrials.gov/ct2/show/NCT01746654? term=gangagen\&rank=1) for studying its effectiveness in reducing the nasal carriage of $S$. aureus in humans. Although there are no lysins being used as medicine yet, it is believed that the breakthrough might come first for treating mucosal infections, such as nasal decolonization and wound healing. Furthermore, the combination of lysins with current antibiotics would be very effective to treat infections caused by multidrug resistant bacteria (Schuch et al., 2014).

Apart from natural lysins, there is an ever-growing interest in the engineered lysins created through modification or rational design from natural lysins. A perfect lysin that is ideal for anti-infective applications should maintain high bioavailability and activity. However, the genus-specific natural lysins are limited when treating infections caused by mixed bacteria from multiple genera. For example, a lysin with a relatively broad lytic spectrum that could lyse more than one genus of pathogens is preferred when treating mucous associated infections (human mucous membranes are the reservoir of many pathogenic bacteria including pneumococci, staphylococci and streptococci) (Coello et al., 1994; De Lencastre et al., 1999; Fischetti, 2003). Lysin engineering is of special promise to create enzybiotics with novel characteristics. 
Chimeric lysins (also called chimeolysins) have been created by shuffling the domains, i.e., the cell wall binding domains (CBDs) and the catalytic domains (CDs) from natural lysins. Interestingly, the natural lysin $\mathrm{Pal}$, identified from pneumococcal phage Dp-1, has proven to be a natural chimeolysin of intergeneric origin (Sheehan et al., 1997). Artificial lysins (also known as artilysins) have been created by fusing a natural lysin or part of its domain with another component that came from either a peptide or a protein. While natural lysins essentially lyse only Gram-positive bacteria exogenously, some artilysins could kill Gram-negative bacteria directly from without (Lukacik et al., 2012; Briers et al., 2014a). Therefore, developing engineered lysins may help to create novel enzybiotics with improved lytic activity and spectrum against both Gram-positive and negative bacterial pathogens, and provide novel clues to understand the modular evolution of lysins (Diaz et al., 1990). This review will outline the characteristics and the remarkable potency of engineered lysins in killing pathogenic bacteria both in vitro and in vivo.

\section{THE ACTION MODEL OF LYSINS}

Differing from the traditional antibiotics, the anti-infective activity of lysin comes from its direct cell lysis upon contact with the bacterial cell wall. Lysins are expressed and accumulated in the cytosol of the host cell at the end of the phage replicative cycle (Young, 1992). With the help of another protein, the holin, lysins get access to their peptidoglycan substrate and cause rapid cell lysis (Wang et al., 2000). The holin-lysin system is essential for host cell lysis, and the molecular mechanisms underlying the procedure of "lysis from within" has been well discussed previously (Young and Wang, 2006).

When applied exogenously as recombinant enzymes, lysins have been demonstrated to cause rapid lysis of Gram-positive bacteria (Loessner et al., 1995). It is this potent ability to cause "lysis from without" of pathogenic Gram-positive cells upon direct contact with peptidoglycan that has laid the foundation of exploiting lysins as enzybiotics (Abedon, 2011). However, in the case of Gram-negative bacteria, the outer membrane hinders the access of lysins to their peptidoglycan substrates in the cell wall and therefore, their antibacterial is limited.

\section{THE MODULAR STRUCTURE OF LYSIN}

Most frequently, lysins displayed a typically modular structure of at least two distinct domains (Villa and Crespo, 2010). That is an N-terminal CD and a C-terminal CBD, corresponding to their two basic functions: enzymatic hydrolysis and substrate recognition (Figure 1). In a few cases, lysins, particularly staphylococcal lysins, have been found to have more than one CDs and one CBD (Navarre et al., 1999; Rigden et al., 2003; Donovan et al., 2006b; Sass and Bierbaum, 2007; Obeso et al., 2008). Extraordinarily, a bacillus phage lysin, plyG, has been shown to have one CD and two separate binding domains, a CBD and a spore binding domain (SBD) (Yang et al., 2012). And the C1 streptococcal phage lysin, $\mathrm{PlyC}$, is shown by crystallization to be a multimeric enzyme composed of eight cell wall binding subunits for each catalytic subunit (Nelson et al., 2006; McGowan et al., 2012).

Although CBD is necessary for most lysins, truncation of some lysins to remove the CBD can result in improved lytic activity without loss of specificity (Loessner et al., 1999; Horgan et al., 2009; Fenton et al., 2010a). One good example is lysin Ply187, the CD from lysin Ply187 (N-terminal 157 amino acids) has a much higher amidase activity than the whole lysin (Loessner et al., 1999).

Generally, the CD gets access to and specifically cleaves the major bonds in the peptidoglycan via the specific recognition of the CBD. The substrates of CBDs are postulated to be unique and conserved molecules in the cell walls that are essential for bacterial viability, usually neutral polysaccharides that are restricted to particular species or even strains. For instance, pneumococcal phage lysin targets choline, an indispensable cell wall molecule for anchoring in S. pneumonia (Garcia et al., 1988; Hermoso et al., 2003). The CBDs of Listeria phage lysins can even distinguish various serotypes of Listeria species in liquid or food samples (Loessner et al., 2002; Schmelcher et al., 2010; Eugster et al., 2011; Eugster and Loessner, 2012). Because of the relatively independent functions of these two domains, engineered lysins can be constructed by shuffling these domains from different origin or fusing them with other molecules. By doing so, the chimera may be empowered with new characteristics, including binding specificity, killing spectrum, solubility, stability, activity and so on.
A

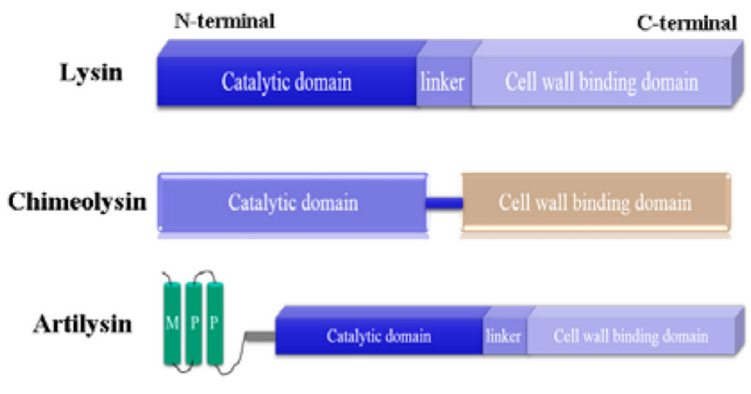

FIGURE 1 | Lysin-based murein hydrolases. (A) The schematic structure of lysin, chimeolysin and artilysin. MPP, membrane penetrating peptides. (B) The cleavage sites of lysin-based murein hydrolases in the peptidoglycan. 1,
B

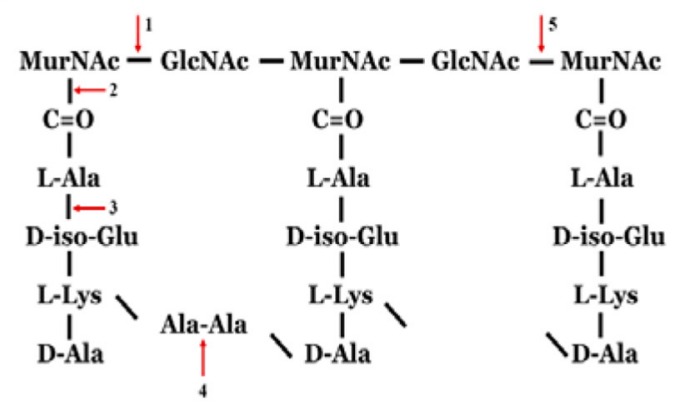

$\mathrm{N}$-acetyl muramidases; 2, N-acetylmuramoyl-L-alanine amidases; 3, L-alanoyl-D-glutamate endopeptidases; 4 , interpeptide bridge endopeptidases; 5 , N-acetyl- $\beta$-D-glucosaminidases. 
Table 1 | The structural composition and characteristics of engineered lysins.

\begin{tabular}{|c|c|c|c|c|c|}
\hline & N-terminal donor & C-terminal donor & Property & Antimicrobial spectrum & Ref. \\
\hline \multicolumn{6}{|l|}{ CHIMEOLYSIN } \\
\hline Clys & $\begin{array}{l}\text { Phage Twort lysin plyTW, } \\
\text { endopeptidase }\end{array}$ & phiNM3 lysin & $\begin{array}{l}\text { Highly soluble, } \\
\text { superiority to mupirocin } \\
\text { for skin decolonization }\end{array}$ & Staphylococci & $\begin{array}{l}\text { Daniel et al., 2010; } \\
\text { Pastagia et al., } 2011\end{array}$ \\
\hline Lys168-87 & $\begin{array}{l}\text { E. faecalis phage } \mathrm{F} 168 / 08 \\
\text { lysin, CHAPa }\end{array}$ & Phage 87 lysin Lys87b & $\begin{array}{l}\text { Highly soluble, broad } \\
\text { antimicrobial activity }\end{array}$ & $\begin{array}{l}\text { Staphylococci, E. faecalis, } \\
\text { E. faecium, S. pyogenes }\end{array}$ & $\begin{array}{l}\text { Fernandes et al., } \\
2012\end{array}$ \\
\hline Lys170-87 & $\begin{array}{l}\text { E. faecalis phage } \mathrm{F} 170 / 08 \\
\text { lysin, amidase }\end{array}$ & Phage 87 lysin Lys $87^{b}$ & $\begin{array}{l}\text { Highly soluble, broad } \\
\text { antimicrobial activity }\end{array}$ & $\begin{array}{l}\text { Staphylococci, E. faecalis, } \\
\text { E. faecium, S. pyogenes }\end{array}$ & $\begin{array}{l}\text { Fernandes et al., } \\
2012\end{array}$ \\
\hline PRF-119 & Phage K lysin plyK, CHAP & $\begin{array}{l}\text { Lysostaphin, SH3b like } \\
\text { domain }\end{array}$ & Very good activity & Staphylococci & $\begin{array}{l}\text { Idelevich et al., } \\
2011\end{array}$ \\
\hline$\lambda$ SA2-E-LysK-SH3b & $\begin{array}{l}\text { Phage } \lambda S A 2 \text { lysin, } \\
\text { endopeptidase }\end{array}$ & LysK, SH3b like domain & $\begin{array}{l}\text { Increased activity and } \\
\text { extended lytic } \\
\text { spectrum }\end{array}$ & Staphylococci, Streptococci & $\begin{array}{l}\text { Becker et al., 2009; } \\
\text { Schmelcher et al., } \\
2012\end{array}$ \\
\hline B30-182-Lyso & $\begin{array}{l}\text { Phage B30 lysin, } \\
\text { endopeptidase }\end{array}$ & $\begin{array}{l}\text { Lysostaphin, SH3b like } \\
\text { domain }\end{array}$ & $\begin{array}{l}\text { Extended lytic } \\
\text { spectrum and binding } \\
\text { capacity }\end{array}$ & $\begin{array}{l}\text { S. aureus, S. uber, } \\
\text { S. agalactiae, } \\
\text { S. dysgalactiae }\end{array}$ & $\begin{array}{l}\text { Donovan et al., } \\
2006 a\end{array}$ \\
\hline Ply187AN-KSH3b & $\begin{array}{l}\text { Phage } 187 \text { lysin Ply } 187, \\
\text { amidase }\end{array}$ & LysK, SH3b like domain & Improved lytic activity & Staphylococci & Mao et al., 2013 \\
\hline $\mathrm{ClyH}$ & $\begin{array}{l}\text { Phage } 187 \text { lysin Ply187, } \\
\text { amidase }\end{array}$ & phiNM3 lysin & $\begin{array}{l}\text { Improved lytic activity } \\
\text { and extended lytic } \\
\text { spectrum }\end{array}$ & Staphylococci, S. sobrinus & Yang et al., 2014 \\
\hline P16-17 & Phage p68 lysin p16, CHAP & $\begin{array}{l}\text { Minor coat protein } 17 \text { of } \\
\text { phage } p 68^{b}\end{array}$ & Highly soluble & S. aureus & $\begin{array}{l}\text { Manoharadas } \\
\text { et al., } 2009\end{array}$ \\
\hline CLL & lysin Cpl-1, lysozyme & LytA C-terminal domain & $\begin{array}{l}\text { Altered binding } \\
\text { capacity }\end{array}$ & Streptococci & Diaz et al., 1990 \\
\hline CLA & LytA amidase domain & $\begin{array}{l}\text { Lysin Cpl-1 binding } \\
\text { domain }\end{array}$ & $\begin{array}{l}\text { Altered binding } \\
\text { capacity }\end{array}$ & Streptococci & Diaz et al., 1990 \\
\hline Art-085 & SMAP-29 peptide & Lysin KZ144 & $\begin{array}{l}\text { Kills Gram-negative } \\
\text { bacteria }\end{array}$ & $\begin{array}{l}\text { P. aeruginosa, P. syringae, } \\
\text { P. putida }\end{array}$ & Briers et al., 2014a \\
\hline Pesticin-like & T4 lysozyme & Pesticin & $\begin{array}{l}\text { Kills Gram-negative } \\
\text { bacteria }\end{array}$ & $\begin{array}{l}\text { Yersinia, E. coli expressing } \\
\text { FyuA }\end{array}$ & Lukacik et al., 2012 \\
\hline LoGT series & $V_{\text {Various peptides }}^{c}$ & Various lysins $^{d}$ & $\begin{array}{l}\text { Kills Gram-negative } \\
\text { bacteria }\end{array}$ & $\begin{array}{l}\text { P. aeruginosa, } A \text {. baumannii, } \\
\text { E. coli, S. Typhimurium }\end{array}$ & Briers et al., 2014b \\
\hline
\end{tabular}

a CHAP: cysteine and histidine-dependent aminopeptidase/hydrolase.

${ }^{b}$ The characters of these CBDs cannot be confirmed for their sequences are unavailable.

cThese peptides include a4, MW1, MW2, polycationic peptide (PCNP), hydrophobic pentapeptide (HPP), Parasin1 (Pa1), and lycotoxin1 (Ly1).

${ }^{d}$ These lysins include OBPgp279 (YP_004958186.1), PVP-SE1gp146 (YP_004893953.1), phiKZgp144 (NP_803710.1), 20142-1gp229 (YP_001956952.1), CR8gp3.5, P2gp09 (NP_046765.1), and PsP3gp10 (NP_958065.1). 


\section{CHIMEOLYSIN}

A chimeolysin could be designed to have an improved lytic activity, or a broader lytic spectrum, compared with its parental enzyme (Table 1). For instance, the specific lytic activity of Ply187AN-KSH3b, a chimeolysin constructed by fusing the amidase of lysin Ply187 with the LysK SH-3b CBD, was 10-fold higher than that of its parental lysin Ply187AN (Mao et al., 2013). Specifically, by adding the non-SH3b-like CBD of phiNM3 to the $\mathrm{CD}$ of Ply187 (giving rises to chimeolysin $\mathrm{ClyH}$ ) yielded a 3.7-13.6 fold increase in lytic activity against $S$. aureus (Yang et al., 2014). ClyH could even lysis S. sobrinus, a streptococci that Ply187 could not lyse at all. Similar results are seen with a chimeolysin Ply187N-V12C, however in this case, the chimeolysin has an extended lytic activity against $S$. dysgalactiae, the main pathogen of cow mastitis (Dong et al., 2014).

In some cases, the lytic spectrum of a chimeolysin may be altered by changing its CBD. The streptococcal $\lambda \mathrm{Sa} 2$ prophage endolysin has a strong lytic activity against multiple streptococcal strains but not staphylococcal pathogens (Donovan and Foster-Frey, 2008). Replacing its Cpl-7 CBD with a staphylococcal $\mathrm{SH} 3 \mathrm{~b}$ domain from either lysostaphin or LysK resulted in a 5-fold increase in staphylolytic activity, and surprisingly, the chimera also maintained significant streptolytic activity (Becker et al., 2009). Similarly, bioengineering different CBDs of Listeria phage lysins provides extended recognition and binding properties (Schmelcher et al., 2011).

Daniel et al. constructed chimeolysins to solve the solubility problems associated with natural lysins. By fusing the $\mathrm{CD}$ of phage Twort lysin to the CBD of phiNM3 lysin, they created a highly soluble chimera, ClyS, which was shown to have potent anti-infective efficacy against MRSA in a murine sepsis model (Daniel et al., 2010). ClyS has also shown superior to mupirocin for skin decolonization of methicillin-resistant and -sensitive S. aureus strains in mice (Pastagia et al., 2011). In another work, Fernandes et al. were able to improve the solubility and antimicrobial activity of Lys87, via substituting its CD with a $\mathrm{CD}$ from an enterococcal lysin that is highly soluble (Fernandes et al., 2012).

There is also an example of a chimeolysin that was designed to avoid resistance to phages. The chimera PRF-119 has been proven to kill four phage-resistant $S$. aureus mutants (Idelevich et al., 2011), and at the same time, showed very good activities against $S$. aureus with MIC 90 of $0.391 \mu \mathrm{g} / \mathrm{ml}$ for $398 \mathrm{MSSA}$ and 776 MRSA clinical isolates, respectively.

\section{ARTILYSIN}

Artilysin denotes an engineered enzybiotic created by fusing a fragment of a natural lysin with peptides or other proteins (Figure 1). One outstanding application is to design artilysins against Gram-negative bacteria (Table 1). In recent research, Briers et al. (2014a) designed an artilysin with a highly efficient antibacterial activity against multidrug resistant strains and persisters of Pseudomonas aeruginosa, by fusing a sheep myeloid antimicrobial peptide with 29 amino acids residues (SMAP-29) to the N-terminus of the endolysin KZ144. SMAP-29 is an $\alpha$ helical cathelicidin found in sheep leukocytes that can pass the outer membrane of Gram-negative bacteria via a self-promoted uptake pathway (Skerlavaj et al., 1999). It is well known that antimicrobial peptides kill bacteria either by disrupting the cytoplasmic membrane or by crossing the membrane and acting on intracellular targets, however, such peptides are cytotoxic to mammalian cells (Maher and McClean, 2006; Dawson and Liu, 2009). Meanwhile, the natural form of lysin KZ144 could not kill $P$. aeruginosa cells directly, but was effective against membranepermeated cells, which are obtained by treatment with chloroform (Briers et al., 2007), or under high hydrostatic pressure (Briers et al., 2008). Surprisingly, the artilysin overcomes the disadvantages of its both donors. The artilysin not only kills the $P$. aeruginosa cells directly, but also shows no cytotoxicity, indicating that the application of bacteriophage lysins as enzybiotics must not be limited only to Gram-positive pathogens.

Very recently, Briers and coworkers described a series of artilysins that are highly active against Gram-negative pathogens. For instance, artilysin LoGT-23, can cause a reduction of $5.5 \mathrm{log}$, $5.2 \log , 2.4 \log$ and $1.5 \log$ for P. aeruginosa, Acinetobacter baumannii, E. coli and Salmonella Typhimurium within $30 \mathrm{~min}$ in the presence of $0.5 \mathrm{mM}$ EDTA, respectively. The in vivo efficacy of some artilysins have also been tested in a Caenorhabditis elegans bacterial infection model, indicating that artilysins may have broad anti-infective applications.

In another example, Lukacik et al. constructed a pesticin-like hybrid toxin that kills specific Yersinia and pathogenic E. coli strains, by attaching an FyuA targeting domain to the N-terminus of T4 lysozyme (Lukacik et al., 2012). The hybrid could pass the out membrane in order to reach the peptidoglycan layer through the interaction with the outer membrane transporter FyuA. Moreover, the hybrid toxin can evade the pesticin immunity protein (Pim) indicating that it may be a potential candidate for in vivo therapy over pesticin. Because FyuA is more common in pathogenic bacteria, the hybrid toxin harbors a great potential to kill pathogenic bacteria specifically.

\section{CONCLUDING REMARKS}

Bacteriophage lysins demonstrate several highly desirable properties compared with antibiotics, which include novel antimicrobial mechanisms, high specificity and activity against multidrug resistant pathogens, as well as a low possibility of developing resistance. The huge number of phages existing on earth supports great resources for lysin discovery. Meanwhile, the modular structure of lysins provides a great chance to create engineered lysins with desired properties, which may include extended killing spectra, enhanced killing activity, and improved solubility. Through rational design of natural lysins, artilysins can even kill Gramnegative bacteria that are resistant to natural lysins. Taken all these together, engineered lysins represent a new class of enzybiotics that are powerful and readily available to fight the emerging antimicrobial resistance.

\section{ACKNOWLEDGMENTS}

This work was supported by the Basic Research Program of the Ministry of Science and Technology of China (2012CB721102), the Chinese Academy of Sciences (KJZD-EW-L02), the National Natural Science Foundation of China (31400126), and the Key Laboratory on Emerging Infectious Diseases and Biosafety, CAS. 


\section{REFERENCES}

Abedon, S. T. (2011). Lysis from without. Bacteriophage 1, 46-49. doi: 10.4161/bact.1.1.13980

Becker, S. C., Foster-Frey, J., Stodola, A. J., Anacker, D., and Donovan, D. M. (2009). Differentially conserved staphylococcal SH3b_5 cell wall binding domains confer increased staphylolytic and streptolytic activity to a streptococcal prophage endolysin domain. Gene 443, 32-41. doi: 10.1016/j.gene.2009.04.023

Briers, Y., Cornelissen, A., Aertsen, A., Hertveldt, K., Michiels, C. W., Volckaert, G., et al. (2008). Analysis of outer membrane permeability of Pseudomonas aeruginosa and bactericidal activity of endolysins KZ144 and EL188 under high hydrostatic pressure. FEMS Microbiol. Lett. 280, 113-119. doi: 10.1111/j.15746968.2007.01051.x

Briers, Y., Volckaert, G., Cornelissen, A., Lagaert, S., Michiels, C. W., Hertveldt, K., et al. (2007). Muralytic activity and modular structure of the endolysins of Pseudomonas aeruginosa bacteriophages phiKZ and EL. Mol. Microbiol. 65, 1334-1344. doi: 10.1111/j.1365-2958.2007.05870.x

Briers, Y., Walmagh, M., Grymonprez, B., Biebl, M., Pirnay, J. P., Defraine, V., et al. (2014a). Art-175 is a highly efficient antibacterial against multidrug-resistant strains and persisters of Pseudomonas aeruginosa. Antimicrob. Agents Chemother. 58, 3774-3784. doi: 10.1128/AAC.02668-14

Briers, Y., Walmagh, M., Van Puyenbroeck, V., Cornelissen, A., Cenens, W., Aertsen, A., et al. (2014b). Engineered endolysin-based "artilysins" to combat multidrug-resistant gram-negative pathogens. MBio 5, e01379-14. doi: 10.1128/mBio.01379-14

Callewaert, L., Walmagh, M., Michiels, C. W., and Lavigne, R. (2011). Food applications of bacterial cell wall hydrolases. Curr. Opin. Biotechnol. 22, 164-171. doi: 10.1016/j.copbio.2010.10.012

Cheng, Q., Nelson, D., Zhu, S., and Fischetti, V. A. (2005). Removal of group $\mathrm{B}$ streptococci colonizing the vagina and oropharynx of mice with a bacteriophage lytic enzyme. Antimicrob. Agents Chemother. 49, 111-117. doi: 10.1128/AAC.49.1.111-117.2005

Coello, R., Jimenez, J., Garcia, M., Arroyo, P., Minguez, D., Fernandez, C., et al. (1994). Prospective study of infection, colonization and carriage of methicillinresistant Staphylococcus aureus in an outbreak affecting 990 patients. Eur. J. Clin. Microbiol. Infect. Dis. 13, 74-81. doi: 10.1007/BF02026130

Daniel, A., Euler, C., Collin, M., Chahales, P., Gorelick, K. J., and Fischetti, V. A. (2010). Synergism between a novel chimeric lysin and oxacillin protects against infection by methicillin-resistant Staphylococcus aureus. Antimicrob. Agents Chemother. 54, 1603-1612. doi: 10.1128/AAC.01625-09

Dawson, R. M., and Liu, C. Q. (2009). Cathelicidin peptide SMAP-29: comprehensive review of its properties and potential as a novel class of antibiotics. Drug Develop. Res. 70, 481-498. doi: 10.1002/ddr.20329

De Lencastre, H., Kristinsson, K. G., Brito-Avo, A., Sanches, I. S., Sa-Leao, R., Saldanha, J., et al. (1999). Carriage of respiratory tract pathogens and molecular epidemiology of Streptococcus pneumoniae colonization in healthy children attending day care centers in Lisbon, Portugal. Microb. Drug Resist. 5, 19-29. doi: $10.1089 / \mathrm{mdr}$.1999.5.19

Diaz, E., Lopez, R., and Garcia, J. L. (1990). Chimeric phage-bacterial enzymes: a clue to the modular evolution of genes. Proc. Natl. Acad. Sci. U.S.A. 87, 8125-8129. doi: 10.1073/pnas.87.20.8125

Dong, Q., Wang, J., Yang, H., Yu, J., Zhang, Y., Huang, Y., et al. (2014). Construction of a chimeric lysin Ply187N-V12C with extended lytic activity against staphylococci and streptococci. Microb. Biotechnol. doi: 10.1111/1751-7915.12166. [Epub ahead of print].

Donovan, D. M., Dong, S., Garrett, W., Rousseau, G. M., Moineau, S., and Pritchard, D. G. (2006a). Peptidoglycan hydrolase fusions maintain their parental specificities. Appl. Environ. Microbiol. 72, 2988-2996. doi: 10.1128/AEM.72.4.2988-2996.2006

Donovan, D. M., and Foster-Frey, J. (2008). LambdaSa2 prophage endolysin requires Cpl-7-binding domains and amidase-5 domain for antimicrobial lysis of streptococci. FEMS Microbiol. Lett. 287, 22-33. doi: 10.1111/j.15746968.2008.01287.x

Donovan, D. M., Lardeo, M., and Foster-Frey, J. (2006b). Lysis of staphylococcal mastitis pathogens by bacteriophage phil1 endolysin. FEMS Microbiol. Lett. 265, 133-139. doi: 10.1111/j.1574-6968.2006.00483.x

Entenza, J. M., Loeffler, J. M., Grandgirard, D., Fischetti, V. A., and Moreillon, P. (2005). Therapeutic effects of bacteriophage Cpl-1 lysin against Streptococcus pneumoniae endocarditis in rats. Antimicrob. Agents Chemother. 49, 4789-4792. doi: 10.1128/AAC.49.11.4789-4792.2005
Eugster, M. R., Haug, M. C., Huwiler, S. G., and Loessner, M. J. (2011). The cell wall binding domain of Listeria bacteriophage endolysin PlyP35 recognizes terminal GlcNAc residues in cell wall teichoic acid. Mol. Microbiol. 81, 1419-1432. doi: 10.1111/j.1365-2958.2011.07774.x

Eugster, M. R., and Loessner, M. J. (2012). Wall teichoic acids restrict access of bacteriophage endolysin Ply118, Ply511, and PlyP40 cell wall binding domains to the Listeria monocytogenes peptidoglycan. J. Bacteriol. 194, 6498-6506. doi: 10.1128/JB.00808-12

Fenton, M., Casey, P. G., Hill, C., Gahan, C. G., Ross, R. P., McAuliffe, O., et al. (2010a). The truncated phage lysin $\mathrm{CHAP}(\mathrm{k})$ eliminates Staphylococcus aureus in the nares of mice. Bioeng. Bugs 1, 404-407. doi: 10.4161/bbug.1.6.13422

Fenton, M., Ross, P., McAuliffe, O., O’Mahony, J., and Coffey, A. (2010b). Recombinant bacteriophage lysins as antibacterials. Bioeng. Bugs 1, 9-16. doi: 10.4161/bbug.1.1.9818

Fernandes, S., Proenca, D., Cantante, C., Silva, F. A., Leandro, C., Lourenco, S., et al. (2012). Novel chimerical endolysins with broad antimicrobial activity against methicillin-resistant Staphylococcus aureus. Microb. Drug Resist. 18, 333-343. doi: $10.1089 / \mathrm{mdr} .2012 .0025$

Fischetti, V. A. (2003). Novel method to control pathogenic bacteria on human mucous membranes. Ann. N.Y. Acad. Sci. 987, 207-214. doi: 10.1111/j.17496632.2003.tb06050.x

Fischetti, V. A. (2005). Bacteriophage lytic enzymes: novel anti-infectives. Trends Microbiol. 13, 491-496. doi: 10.1016/j.tim.2005.08.007

Fischetti, V. A. (2006). Using phage lytic enzymes to control pathogenic bacteria. BMC Oral Health 6(Suppl. 1):S16. doi: 10.1186/1472-6831-6-S1-S16

Fischetti, V. A. (2008). Bacteriophage lysins as effective antibacterials. Curr. Opin. Microbiol. 11, 393-400. doi: 10.1016/j.mib.2008.09.012

Fischetti, V. A. (2010). Bacteriophage endolysins: a novel anti-infective to control gram-positive pathogens. Int. J. Med. Microbiol. 300, 357-362. doi: 10.1016/j.ijmm.2010.04.002

Fischetti, V. A., Nelson, D., and Schuch, R. (2006). Reinventing phage therapy: are the parts greater than the sum? Nat. Biotechnol. 24, 1508-1511. doi: $10.1038 /$ nbt1206-1508

Garcia, E., Garcia, J. L., Garcia, P., Arraras, A., Sanchez-Puelles, J. M., and Lopez, R. (1988). Molecular evolution of lytic enzymes of Streptococcus pneumoniae and its bacteriophages. Proc. Natl. Acad. Sci. U.S.A. 85, 914-918. doi: 10.1073/pnas.85.3.914

George, S. E., Chikkamadaiah, R., Durgaiah, M., Joshi, A. A., Thankappan, U. P., Madhusudhana, S. N., et al. (2012). Biochemical characterization and evaluation of cytotoxicity of antistaphylococcal chimeric protein P128. BMC Res. Notes 5:280. doi: 10.1186/1756-0500-5-280

Gilmer, D. B., Schmitz, J. E., Euler, C. W., and Fischetti, V. A. (2013). Novel bacteriophage lysin with broad lytic activity protects against mixed infection by Streptococcus pyogenes and methicillin-resistant Staphylococcus aureus. Antimicrob. Agents Chemother. 57, 2743-2750. doi: 10.1128/AAC. 02526-12

Grandgirard, D., Loeffler, J. M., Fischetti, V. A., and Leib, S. L. (2008). Phage lytic enzyme Cpl-1 for antibacterial therapy in experimental pneumococcal meningitis. J. Infect. Dis. 197, 1519-1522. doi: 10.1086/587942

Hermoso, J. A., Monterroso, B., Albert, A., Galan, B., Ahrazem, O., Garcia, P., et al. (2003). Structural basis for selective recognition of pneumococcal cell wall by modular endolysin from phage Cp-1. Structure 11, 1239-1249. doi: 10.1016/j.str.2003.09.005

Horgan, M., O’Flynn, G., Garry, J., Cooney, J., Coffey, A., Fitzgerald, G. F., et al. (2009). Phage lysin LysK can be truncated to its CHAP domain and retain lytic activity against live antibiotic-resistant staphylococci. Appl. Environ. Microbiol. 75, 872-874. doi: 10.1128/AEM.01831-08

Idelevich, E. A., Von Eiff, C., Friedrich, A. W., Iannelli, D., Xia, G., Peters, G., et al. (2011). In vitro activity against Staphylococcus aureus of a novel antimicrobial agent, PRF-119, a recombinant chimeric bacteriophage endolysin. Antimicrob. Agents Chemother. 55, 4416-4419. doi: 10.1128/AAC. 00217-11

Junjappa, R. P., Desai, S. N., Roy, P., Narasimhaswamy, N., Raj, J. R., Durgaiah, M., et al. (2013). Efficacy of anti-staphylococcal protein P128 for the treatment of canine pyoderma: potential applications. Vet. Res. Commun. 37, 217-228. doi: 10.1007/s11259-013-9565-y

Kiser, K. B., Cantey-Kiser, J. M., and Lee, J. C. (1999). Development and characterization of a Staphylococcus aureus nasal colonization model in mice. Infect. Immun. 67, 5001-5006. 
Knoll, B. M., and Mylonakis, E. (2014). Antibacterial bioagents based on principles of bacteriophage biology: an overview. Clin. Infect. Dis. 58, 528-534. doi: $10.1093 / \mathrm{cid} / \mathrm{cit} 771$

Loeffler, J. M., Nelson, D., and Fischetti, V. A. (2001). Rapid killing of Streptococcus pneumoniae with a bacteriophage cell wall hydrolase. Science 294, 2170-2172. doi: 10.1126/science.1066869

Loessner, M. J. (2005). Bacteriophage endolysins-current state of research and applications. Curr. Opin. Microbiol. 8, 480-487. doi: 10.1016/j.mib.2005.06.002

Loessner, M. J., Gaeng, S., and Scherer, S. (1999). Evidence for a holin-like protein gene fully embedded out of frame in the endolysin gene of Staphylococcus aureus bacteriophage 187. J. Bacteriol. 181, 4452-4460.

Loessner, M. J., Kramer, K., Ebel, F., and Scherer, S. (2002). C-terminal domains of Listeria monocytogenes bacteriophage murein hydrolases determine specific recognition and high-affinity binding to bacterial cell wall carbohydrates. Mol. Microbiol. 44, 335-349. doi: 10.1046/j.1365-2958.2002. 02889.x

Loessner, M. J., Schneider, A., and Scherer, S. (1995). A new procedure for efficient recovery of DNA, RNA, and proteins from Listeria cells by rapid lysis with a recombinant bacteriophage endolysin. Appl. Environ. Microbiol. 61, 1150-1152.

Lukacik, P., Barnard, T. J., Keller, P. W., Chaturvedi, K. S., Seddiki, N., Fairman, J. W., et al. (2012). Structural engineering of a phage lysin that targets gram-negative pathogens. Proc. Natl. Acad. Sci. U.S.A. 109, 9857-9862. doi: 10.1073/pnas.1203472109

Maher, S., and McClean, S. (2006). Investigation of the cytotoxicity of eukaryotic and prokaryotic antimicrobial peptides in intestinal epithelial cells in vitro. Biochem. Pharmacol. 71, 1289-1298. doi: 10.1016/j.bcp.2006.01.012

Manoharadas, S., Witte, A., and Blasi, U. (2009). Antimicrobial activity of a chimeric enzybiotic towards Staphylococcus aureus. J. Biotechnol. 139, 118-123. doi: 10.1016/j.jbiotec.2008.09.003

Mao, J., Schmelcher, M., Harty, W. J., Foster-Frey, J., and Donovan, D. M. (2013). Chimeric Ply187 endolysin kills Staphylococcus aureus more effectively than the parental enzyme. FEMS Microbiol. Lett. 1, 30-36. doi: 10.1111/1574-6968.12104

McGowan, S., Buckle, A. M., Mitchell, M. S., Hoopes, J. T., Gallagher, D. T., Heselpoth, R. D., et al. (2012). X-ray crystal structure of the streptococcal specific phage lysin PlyC. Proc. Natl. Acad. Sci. U.S.A. 109, 12752-12757. doi: 10.1073/pnas.1208424109

Navarre, W. W., Ton-That, H., Faull, K. F., and Schneewind, O. (1999). Multiple enzymatic activities of the murein hydrolase from staphylococcal phage phil1. Identification of a D-alanyl-glycine endopeptidase activity. J. Biol. Chem. 274, 15847-15856. doi: 10.1074/jbc.274.22.15847

Nelson, D., Schuch, R., Chahales, P., Zhu, S., and Fischetti, V. A. (2006). PlyC: a multimeric bacteriophage lysin. Proc. Natl. Acad. Sci. U.S.A. 103, 10765-10770. doi: 10.1073/pnas.0604521103

Obeso, J. M., Martinez, B., Rodriguez, A., and Garcia, P. (2008). Lytic activity of the recombinant staphylococcal bacteriophage PhiH5 endolysin active against Staphylococcus aureus in milk. Int. J. Food Microbiol. 128, 212-218. doi: 10.1016/j.ijfoodmicro.2008.08.010

Oliveira, H., Azeredo, J., Lavigne, R., and Kluskens, L. D. (2012). Bacteriophage endolysins as a response to emerging foodborne pathogens. Trends Food Sci. Technol. 28, 103-115. doi: 10.1016/j.tifs.2012.06.016

Pastagia, M., Euler, C., Chahales, P., Fuentes-Duculan, J., Krueger, J. G., and Fischetti, V. A. (2011). A novel chimeric lysin shows superiority to mupirocin for skin decolonization of methicillin-resistant and -sensitive Staphylococcus aureus strains. Antimicrob. Agents Chemother. 55, 738-744. doi: 10.1128/AAC.00890-10

Pastagia, M., Schuch, R., Fischetti, V. A., and Huang, D. B. (2013). Lysins: the arrival of pathogen-directed anti-infectives. J. Med. Microbiol. 62, 1506-1516. doi: 10.1099/jmm.0.061028-0

Rashel, M., Uchiyama, J., Ujihara, T., Uehara, Y., Kuramoto, S., Sugihara, S., et al. (2007). Efficient elimination of multidrug-resistant Staphylococcus aureus by cloned lysin derived from bacteriophage phi MR11. J. Infect. Dis. 196, 1237-1247. doi: 10.1086/521305

Rigden, D. J., Jedrzejas, M. J., and Galperin, M. Y. (2003). Amidase domains from bacterial and phage autolysins define a family of gamma-D,L-glutamatespecific amidohydrolases. Trends Biochem. Sci. 28, 230-234. doi: 10.1016/S09680004(03)00062-8

Sass, P., and Bierbaum, G. (2007). Lytic activity of recombinant bacteriophage phil1 and phi12 endolysins on whole cells and biofilms of Staphylococcus aureus. Appl. Environ. Microbiol. 73, 347-352. doi: 10.1128/AEM.01616-06
Schmelcher, M., Powell, A. M., Becker, S. C., Camp, M. J., and Donovan, D. M. (2012). Chimeric phage lysins act synergistically with lysostaphin to kill mastitis-causing Staphylococcus aureus in murine mammary glands. Appl. Environ. Microbiol. 78, 2297-2305. doi: 10.1128/AEM.07050-11

Schmelcher, M., Shabarova, T., Eugster, M. R., Eichenseher, F., Tchang, V. S., Banz, M., et al. (2010). Rapid multiplex detection and differentiation of Listeria cells by use of fluorescent phage endolysin cell wall binding domains. Appl. Environ. Microbiol. 76, 5745-5756. doi: 10.1128/AEM.00801-10

Schmelcher, M., Tchang, V. S., and Loessner, M. J. (2011). Domain shuffling and module engineering of Listeria phage endolysins for enhanced lytic activity and binding affinity. Microb. Biotechnol. 4, 651-662. doi: 10.1111/j.17517915.2011.00263.x

Schuch, R., Lee, H. M., Schneider, B. C., Sauve, K. L., Law, C., Khan, B. K., et al. (2014). Combination therapy with lysin CF-301 and antibiotic is superior to antibiotic alone for treating methicillin-resistant Staphylococcus aureus-induced murine bacteremia. J. Infect. Dis. 209, 1469-1478. doi: 10.1093/infdis/jit637

Schuch, R., Nelson, D., and Fischetti, V. A. (2002). A bacteriolytic agent that detects and kills Bacillus anthracis. Nature 418, 884-889. doi: 10.1038/nature01026

Sheehan, M. M., Garcia, J. L., Lopez, R., and Garcia, P. (1997). The lytic enzyme of the pneumococcal phage Dp-1: a chimeric lysin of intergeneric origin. Mol. Microbiol. 25, 717-725. doi: 10.1046/j.1365-2958.1997.5101880.x

Singh, P. K., Donovan, D. M., and Kumar, A. (2014). Intravitreal injection of the chimeric phage endolysin Ply187 protects mice from Staphylococcus aureus endophthalmitis. Antimicrob. Agents Chemother. 58, 4621-4629 doi: 10.1128/AAC.00126-14

Skerlavaj, B., Benincasa, M., Risso, A., Zanetti, M., and Gennaro, R. (1999). SMAP29: a potent antibacterial and antifungal peptide from sheep leukocytes. FEBS Lett. 463, 58-62. doi: 10.1016/S0014-5793(99)01600-2

Villa, T. G., and Crespo, P. V. (2010). Enzybiotics: Antibiotic Enzymes as Drugs and Therapeutics. Hoboken, NJ: John Wiley \& Sons.

Vipra, A. A., Desai, S. N., Roy, P., Patil, R., Raj, J. M., Narasimhaswamy, N., et al. (2012). Antistaphylococcal activity of bacteriophage derived chimeric protein P128. BMC Microbiol. 12:41. doi: 10.1186/1471-2180-12-41

Wang, I. N., Smith, D. L., and Young, R. (2000). Holins: the protein clocks of bacteriophage infections. Annu. Rev. Microbiol. 54, 799-825. doi: 10.1146/annurev.micro.54.1.799

Witzenrath, M., Schmeck, B., Doehn, J. M., Tschernig, T., Zahlten, J., Loeffler, J. M., et al. (2009). Systemic use of the endolysin Cpl-1 rescues mice with fatal pneumococcal pneumonia. Crit. Care Med. 37, 642-649. doi: 10.1097/CCM.0b013e31819586a6

Yang, H., Wang, D. B., Dong, Q., Zhang, Z., Cui, Z., Deng, J., et al. (2012). Existence of separate domains in lysin PlyG for recognizing Bacillus anthracis spores and vegetative cells. Antimicrob. Agents Chemother. 56, 5031-5039. doi: 10.1128/AAC.00891-12

Yang, H., Zhang, Y., Yu, J., Huang, Y., Zhang, X. E., and Wei, H. (2014). Novel chimeric lysin with high-level antimicrobial activity against methicillinresistant Staphylococcus aureus in vitro and in vivo. Antimicrob. Agents Chemother. 58, 536-542. doi: 10.1128/AAC.01793-13

Young, R. (1992). Bacteriophage lysis: mechanism and regulation. Microbiol. Rev. 56, 430-481.

Young, R., and Wang, I. (2006). "Phage lysis," in The Bacteriophages, ed R. Calendar (Oxford: Oxford University Press), 104-126.

Conflict of Interest Statement: The authors declare that the research was conducted in the absence of any commercial or financial relationships that could be construed as a potential conflict of interest.

Received: 23 August 2014; accepted: 29 September 2014; published online: 16 October 2014.

Citation: Yang H, Yu J and Wei H (2014) Engineered bacteriophage lysins as novel anti-infectives. Front. Microbiol. 5:542. doi: 10.3389/fmicb.2014.00542

This article was submitted to Antimicrobials, Resistance and Chemotherapy, a section of the journal Frontiers in Microbiology.

Copyright (C) 2014 Yang, Yu and Wei. This is an open-access article distributed under the terms of the Creative Commons Attribution License (CC BY). The use, distribution or reproduction in other forums is permitted, provided the original author(s) or licensor are credited and that the original publication in this journal is cited, in accordance with accepted academic practice. No use, distribution or reproduction is permitted which does not comply with these terms. 